\title{
Editorial
}

\section{Medicolegal Issues in ENT Practice}

\section{Introduction}

In Europe, America and any other developed countries all doctors are working with medical insurance coverage .If there is any malpractice, negligence, any harm or even death occurs the patient or patient's party can sue a case against that particular doctor and in most of the cases if that claim is proved then indemnity or compensations is paid by the insurance company. In Bangladesh we all are working without any insurance cover and for the last couple of years not only in ENT but many of our professional colleagues are facing many medicolegal issues, a lot of complains against physicians is raised and some of them have a direct impact on physicians life and career. In most of the cases in Bangladesh, media play a negative role, some third party come forward with ill motive and doctors are in a great harassment.

Consent and miscommunications is one of most important points which lead to complains against surgeons in Otolaryngology and in other medical discipline. Documentations and using of unusual terms is another well known reason of errors in medicine general and ENT specifically. Addressing the law of each country regarding physicians who are practicing is very vital.

\section{What is Malpractice?}

Malpractice is described as negligence or misconduct that injures a patient who is treated under standard conditions by a physician or surgeon. Our local medical association has announced that malpractice is also involved when a patient incurs harm due to lack of information, experience or attention, and that can include failure or delay in diagnosis, improper performance, complication of surgery or inadequate postoperative management. In recent years, malpractice litigations against physicians have increased. Socioeconomic status of countries, innovations in medical practices, increased awareness in society, development of insurance systems, and high education level may be the cause of this increasing trend. Physicians should be educated in the medicolegal aspects of malpractice and awareness should be raised accordingly to overcome the situation.

\section{Medicolegal Aspects}

For a claim in negligence to succeed, the claimant must prove 3 things

1. That the doctor owed them a duty of care. If any patient consults a doctor, and doctor offers any advice or treatment the doctor has undertaken the duty of care towards that patient.

2. That the doctors practice fell below an acceptable standard of care. For many years, the Courts used the Bolam principle alone to judge the standard of medical care delivered. This principle states:" he is not guilty of negligence if he has acted in accordance with a practice accepted as proper by a responsible body of medical men skilled in that particular art"

3. That the patient suffered harm as a direct result of that substandard care. This is often the hardest point of the three to prove and many claims fail. For example 
a patient bringing a claim against a surgeon who did not diagnose cancer promptly would have to prove that this delay directly harmed his or her clinical outcome.

The claim process must commence within the required statutory time frame. If negligence is proven, it results in liability for compensation for the injured patient for the harm suffered as a result of the negligence.

\section{Negligence in the context of Invalid Consent:}

A patient may successfully sue his or her doctor in negligence if he or she proves that the information he or she was given and on which he or she based his or her consent to treatment was deficient in some way. If she or he can demonstrate this and convince the court the following:

a) He or she would not have agreed to treatment if he or she had been in possession of the correct information.

b) The harm he or she suffered was a direct result of this treatment. Then the claim may be successful.

\section{Claims related to Otolaryngology}

Medical negligence claims fall into three broad groups:

1. Delay in or failure to make a diagnosis.

2. A recognized complication occurs after a surgical procedure.

3. An adverse outcome of treatment (both medical and surgical.

In the first group the typical scenarios include a patient with vague otological symptoms later found to have an acoustic neuroma; patients with globus like symptoms who are subsequently found to have oesophageal cancer or otalgia with tongue base or tonsillar carcinoma.
In the second group the case may be argued on the point that the surgeon's skills were inadequate but is more normally fought around the quality and content of the consent process. Typical scenarios include recurrent laryngeal nerve damage following thyroid surgery, facial nerve damage following parotid or mastoid surgeries, accessory nerve damage in neck dissection, orbital complications and CSF leak following endoscopic sinus surgery, reactionary or secondary haemorrhage following tonsillectomy.

In this situation the criticism of a surgeon's skill is normally defended particularly if he or she performs regularly and he or she has audit data about it's outcome, however it is an argument for avoiding occasional surgery. With regards to consent, the claimant will argue that the surgeon did not mention or explained details of any complications and had this been done, they would not have proceeded to that operation. Further it is extremely important to explain to the patient the option of no treatment at all, and the potential consequences of that. This can be more easily defended with supportive and thorough documentation.

Finally the third group represents a more difficult area and mostly due to lack of communication between the clinicians and patients. Often there are unrealistic expectations of outcome and a subsequent failure to acknowledge this in an angry patient. Typical scenarios include dissatisfaction with appearance after cosmetic surgery or rhinoplasty, failure to address symptoms with nasal surgery or poor hearing after ear surgery.

One study from the Department of Otolaryngology, Istanbul University, Medical Faculty by Mehmet et al showed that thyroidectomy is the main cause of malpractice claims, tonsillectomy is the most 
common cause of death, and the second most common cause of malpractice claims.

\section{Medical records:}

The primary purpose of medical records is to support ongoing patient care, provide a crucial source of information in health care system. Records must.

a) Be clear, accurate and legible including date and time and duly signed by the doctor

b) Be made during or after each episode of patient care.

c) Record every consultation, discussions about patient,s care, possible complications of surgery, treatment outcome, any alternative to surgery, future management plan, palliative care etc.

d) Not be altered, amended or added after original episode of care.

e) Avoid abbreviations.

f) Record abnormal test results.

g) Records must be stored and retained for future use or research.

\section{Unaware of common laws:}

Despite the fact that judicial systems regarding malpractice differ between countries, similar risks, issues, and outcomes exist, and physicians are typically unaware of the medicolegal aspects of their specialty until faced with a lawsuit alleging malpractice. Therefore, all physicians should at least be aware of common legal terms and medicolegal aspects of their specialty, and duties that both a plaintiff and a defendant have in a case of malpractice. In our legal system, there are no substances in the field of criminal or civil law that regulate criminal and legal responsibility of physicians. In order for physicians to be legally accountable, an improper performance is needed. Investigation of malpractice claims is a technical matter and therefore the judge asks the expert doctors (member of NIFM) if there has been such a fault.

\section{Conclusion}

There is no guarantee to overcome any complaints in medicine or surgery but the following measures can be taken to minimize the risk.

a) Time is taken to establish a good relationship with the patient.

b) Time is taken to explain the diagnosis and any treatment plans and the patient should understand that. Informed consent is to be taken in every step of treatment stage.

c) Patient should not be forced to have surgery even it is a right decision.

d) Finally everything should be documented and stored for future reference.

\section{A Matin}

Professor \& Head

Department of ENT \& HNS

Shaheed Suhrawardy Medical College

Sher-E-Bangla Nagar, Dhaka

E-mail:matinfrcs@yahoo.com 